\title{
BIOESTIMULANTES APLICADOS ÀS SEMENTES E FOLHAS DE MUDAS DE MARACUJAZEIRO-AMARELO
}

\author{
Ester Foelkel ${ }^{1}$, Milena Aparecida Ferrari Mateus ${ }^{2}$, Átila Francisco Mógor ${ }^{3}$, Eduardo Cesar \\ Brugnara $^{4}$
}

${ }^{1}$ Doutoranda em Produção Vegetal do Departamento de Fitotecnia e Fitossanitarismo, Universidade Federal do Paraná, Curitiba - PR.

${ }^{2}$ Bolsista de extensão no país do CNPq -nível B, Universidade Federal da Fronteira Sul, Laranjeiras do Sul PR.

${ }^{3}$ Professor Associado do Departamento de Fitotecnia e Fitossanitarismo, Universidade Federal do Paraná, Curitiba - PR.

${ }^{4}$ Pesquisador do Centro de Pesquisa para Agricultura Familiar - EPAGRI, Chapecó - SC.

RESUMO: O objetivo deste trabalho foi avaliar o efeito de dois produtos com ação bioestimulante, Acadian ${ }^{\circledR}$ e Biozyme $\mathrm{TS}^{\circledR}$, na emergência, no crescimento e em parâmetros morfofisiológicos de mudas de maracujazeiro-amarelo. Foram executados dois experimentos de outubro a dezembro de 2012. No primeiro, em Curitiba - PR, a aplicação dos produtos foi feita por imersão de sementes e a avaliação até os 40 dias após a semeadura. No segundo, em Pinhais, PR, a aplicação foi feita por pulverização foliar e a avaliação realizada até 60 dias após a semeadura. As concentrações testadas foram: 0, 2, 4 e 6 mL.L $L^{-1}$ em solução aquosa. $O$ aumento da concentração dos produtos via semente incrementou linearmente a matéria seca da parte aérea das mudas, mas não houve efeito na emergência, altura, número de folhas e no crescimento radicular. A aplicação via foliar até a concentração de 3,15 mL.L ${ }^{-1}$ aumentou o teor de clorofila nas folhas. Também houve aumento da quantidade de raízes grossas com o aumento da concentração dos produtos, porém o comprimento total das raízes e os parâmetros da parte aérea não foram afetados. Como conclusão, a aplicação de Biozyme $\mathrm{TS}^{\circledR}$ e de Acadian $^{\circledR}$ às sementes, até as concentrações de $6 \mathrm{~mL} . \mathrm{L}^{-1}$, aumenta a matéria seca da parte aérea de plântulas de maracujazeiro-amarelo. A aplicação via foliar aumenta a quantidade de raízes grossas, e nas concentrações de 3,15 mL.L $\mathrm{L}^{-1}$ promove o maior teor relativo de clorofila nas folhas.

Palavras-chave: Passiflora edulis f. flavicarpa. Bioestimulantes. Emergência. Fisiologia. Ascophyllum nodosum.

\section{BIOSTIMULANTS APPLYED TO SEEDS AND SHOOT OF SEEDLINGS OF YELLOW PASSION FRUIT}

\begin{abstract}
The objective of this work was to evaluate the effect of two products with biostimulant action, Acadian ${ }^{\circledR}$ and Biozyme $\mathrm{TS}^{\circledR}$, on the emergence, growth and some morpho-physiological parameters of yellow passion fruit seedlings. Two experiments were performed from October to December 2012. In the first, in Curitiba - PR, the products were applied to the seeds by dipping and the evaluation was performed until 40 days after seeding. In the second, in Pinhais - PR, the products were applied by spraying the leaves
\end{abstract}


and evaluations were effected until 60 days after seeding. The concentrations tested were 0 , 2, 4 e 6 mL.L ${ }^{-1}$ in water solution. The raising in the concentration applied to the seeds resulted in linear increase in shoot dry weight, but no effect was observed in emergence, shoot length, leaf number and root growth. The application to the leaves until $3.15 \mathrm{~mL} . \mathrm{L}^{-1}$ increased leaf chlorophyll content. There was enhancement in the quantity of thick roots as the concentration was raised until $6 \mathrm{~mL} . \mathrm{L}^{-1}$. However, the total root length and the shoot parameters were not affected. As conclusion, the application of Biozyme TS $^{\circledR}$ and Acadian ${ }^{\circledR}$ in the seeds until concentration of $6 \mathrm{~mL} . \mathrm{L}^{-1}$ increases the shoot dry weight of yellow passion fruit seedling. The application in the leaves increases the quantity of thick roots, while in concentration of $3.15 \mathrm{~mL} . \mathrm{L}^{-1}$ it induces higher relative chlorophyll content in the leaves.

Key words: Passiflora edulis f. flavicarpa. Biostimulants. Emergence. Physiology. Ascophyllum nodosum.

\section{INTRODUÇÃO}

A cultura do maracujazeiro (Passiflora spp.) ocupou cerca de 60 mil hectares no Brasil em 2012, em que foram produzidas mais de 920 mil toneladas, que atingiram o valor 851 milhões de reais. O Estado da Bahia apresentou a maior área cultivada (INSTITUTO BRASILEIRO DE GEOGRAFIA E ESTATÍSTICA - IBGE, 2014). A principal espécie cultivada é o maracujazeiro-amarelo (Passiflora edulis Sims f. flavicarpa Deg.). Um dos principais entraves na produção da fruta é a falta de qualidade das mudas (FERREIRA et al., 2007).

O desenvolvimento inicial das plantas está altamente relacionado com boas condições nutricionais (PRADO; NATALE; ROZANE, 2006), as quais podem ser supridas pelo uso freqüente de certos bioestimulantes (FERREIRA et al., 2007). Entretanto, espera-se desses produtos efeito além do exclusivamente nutricional, pois podem conter em sua composição extratos de algas, aminoácidos ou outros compostos orgânicos com atuação no metabolismo vegetal (MÓGOR et al., 2008). Alguns dos compostos contidos nos bioestimulantes podem estimular a síntese de hormônios vegetais, promovendo melhorias tanto na germinação quanto no desenvolvimento inicial de plântulas (KHAN et al., 2009).

O interesse no uso de extrato da alga Ascophyllum nodosum como bioprotetor ou bioestimulante é crescente, inclusive no Brasil, para diversas culturas como as cucurbitáceas (PERES et al., 2012), morangueiro (NESI et al., 2013;), tomate (KOYAMA et al., 2012) e também maracujazeiro (OLIVEIRA et al., 2011). Os efeitos da aplicação de extratos de algas em plantas não podem ser atribuídos somente à sua composição mineral. Eles contém polissacarídeos, aminoácidos, alem de citocininas e auxinas naturais (KHAN et al., 2009). O emprego de compostos naturais com ação similar a de reguladores vegetais, associados com fertilizantes foliares, também podem ter efeitos. O Biozyme $\mathrm{TS}^{\circledR}$, derivado de extrato vegetal, pode promover aumento do desenvolvimento vegetativo em algumas espécies, tendo seu uso em ascensão para diversas culturas; todavia, não há estudos na literatura para passifloráceas.

Cultura Agronômica, Ilha Solteira, v.24, n.2, p.135-148, 2015 
O objetivo deste trabalho foi avaliar o efeito de dois bioestimulantes comerciais, Acadian $^{\circledR}$ e Biozyme TS ${ }^{\circledR}$, aplicados via semente e por aspersão nas folhas, na emergência, no crescimento e em parâmetros morfofisiológicos de mudas de maracujazeiro-amarelo.

\section{MATERIAL E MÉTODOS}

Para a realização do trabalho, foram realizados dois experimentos independentes. Em ambos utilizaram-se as sementes de maracujazeiro-amarelo (Passiflora edulis fs. flavicarpa) do genótipo Ovalado Grande (procedente da Epagri - Estação Experimental de Urussanga, Urussanga, SC), e os bioestimulantes Biozyme $\mathrm{TS}^{\circledR}$ e Acadian ${ }^{\circledR}$. Biozyme TS $^{\circledR}$ é um composto de origem vegetal que apresenta em sua composição 77 ppm de giberelinas, 33 ppm de ácido indolacético, 128,7 ppm de zeatina, 0,44 \% de enxofre, 0,14\% de MgO, 0,3 $\%$ de Boro, 0,49 \% de ferro, 0,12 \% de magnésio e 0,37\% de zinco (segundo o fabricante). Acadian $^{\circledR}$ é fabricado a partir da alga Ascophyllum nodosum, na concentração de $29 \%$, e contém ainda estabilizantes e hidróxido de potássio, 61,48g/1 de $\mathrm{K}_{2} \mathrm{O}$ solúvel em água, 69,6 g. $\mathrm{L}^{-1}$ de carbono orgânico total (OLIVEIRA et al., 2011).

\section{Experimento 1}

O primeiro experimento foi conduzido em Curitiba-PR, Brasil, em câmara de nebulização que dispunha de irrigação por nebulização intermitente com bicos de vazão de $48 \mathrm{~L} \cdot \mathrm{h}^{-1}$. O tempo de irrigação foi de $15 \mathrm{~s}$ e o turno variável: entre 8 e $17 \mathrm{~h}$ a cada $15 \mathrm{~min}$, das 17 às $23 \mathrm{~h}$ a cada $60 \mathrm{~min}$ e das 23 às $8 \mathrm{~h}$ a cada $180 \mathrm{~min}$. Os tratamentos foram compostos pela combinação dos fatores bioestimulante (Biozyme TS $^{\circledR}$ e Acadian ${ }^{\circledR}$ ) e sua concentração ( 0 - testemunha, 2, 4 e $\left.6 \mathrm{~mL} . \mathrm{L}^{-1}\right)$, em delineamento experimental inteiramente casualizado, com quatro repetições de 50 sementes, semelhante ao utilizado por Rosseto et al. (2000). As 200 sementes utilizadas em cada tratamento foram embebidas em $30 \mathrm{ml}$ da solução de tratamento por 24 horas. Após, em 02 de outubro de 2012, foram semeadas em bandejas de isopor com 200 células $\left(10 \mathrm{~cm}^{3}\right.$ por célula), contendo substrato comercial para vasos e floreiras Garden Plus ${ }^{\circledR}$.

A cada três dias e até a estabilização registrou-se a emergência das plântulas, em que se considerou como emergidas as que apresentaram o primeiro par de folhas cotiledonares totalmente separado, semelhante ao realizado por Ferreira et al. (2007). Aos 40 dias após a semeadura (DAS) foram avaliados o número de folhas, o comprimento do caule, a área foliar, o comprimento total de raízes e o comprimento de raízes por classes de diâmetro, com amplitude de $0,5 \mathrm{~mm}$. A área foliar e o comprimento de raízes foram medidos com um medidor de área Win Rhyzzo ${ }^{\circledR}$. Na contagem de folhas, consideraram-se apenas as que apresentavam as bordas separadas. A parte aérea e a radicular das plantas foram acondicionadas em estufa $\left(75^{\circ} \mathrm{C}\right.$, com circulação forçada de ar) e após uma semana efetuouse a pesagem da matéria seca. Calculou-se a percentagem de emergência e o índice de velocidade de emergência (IVE) seguindo metodologia proposta por Lima, Caldas e Santos (2006).

Cultura Agronômica, Ilha Solteira, v.24, n.2, p.135-148, 2015 


\section{Experimento 2}

O segundo experimento foi conduzido em casa de vegetação localizada no município de Pinhais - PR. Foram utilizados sacos plásticos perfurados $\left(580 \mathrm{~cm}^{3}\right)$ contendo substrato comercial (Garden Plus®), onde se procedeu a semeadura no dia 03 de outubro de 2012. A irrigação foi realizada manualmente. Os tratamentos foram compostos pela combinação dos

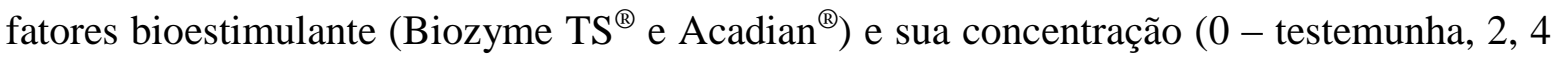
e $6 \mathrm{~mL}$. $\left.\mathrm{L}^{-1}\right)$, em delineamento experimental inteiramente casualizados, com quatro repetições de quatro plantas. Durante o crescimento das mudas, foram realizadas duas pulverizações com os diferentes tratamentos, aos 30 e 45 DAS. Foi utilizado um pulverizador manual com vazão de $150 \mathrm{~mL} \cdot \mathrm{min}^{-1}$ com pulverização até o completo molhamento das folhas, sem escorrimento. Na semana posterior a cada pulverização o teor relativo de clorofila foi medido com o clorofilômetro (N-Tester ${ }^{\circledR}$ ) nas duas folhas mais jovens e completamente expandidas. Aos 60 DAS foram avaliadas as seguintes variáveis: número de folhas por planta, área foliar, massa da matéria seca e comprimento do sistema radicular, de forma semelhante ao experimento 1.

\section{Análise de dados}

Os dados dos dois experimentos foram analisados utilizando-se o aplicativo R, pacote ExpDes (FERREIRA; CAVALCANTI; NOGUEIRA, 2011). Foram realizadas análises de variâncias em esquema fatorial (2 bioestimulantes x 4 concentrações) e quando observado efeito significativo de concentrações aplicou-se uma análise de regressão linear.

\section{RESULTADOS E DISCUSSÃO}

\section{Experimento 1}

Na Tabela 1 são apresentados os valores de probabilidade de erro tipo I $(p)$ e coeficientes de variação para as variáveis avaliadas no experimento 1 .

A porcentagem de emergência variou de 68,5 a $71 \%$ (Tabela 2), sem diferenças significativas entre os tratamentos. A germinação iniciou 16 dias após a semeadura e estendeu-se até $37^{\circ}$ dia. O IVE não foi influenciado pelos tratamentos e variou de 20,5 a 21.

Vários trabalhos demonstraram efeito positivo da aplicação de reguladores de crescimento na emergência de sementes de maracujazeiro-amarelo e outras passifloráceas (ROSSETO et al., 2000; LIMA et al., 2009; ZUCARELI et al., 2009). Entretanto, se tomarmos como exemplo a concentração de $6 \mathrm{~mL} \cdot \mathrm{L}^{-1}$ de Biozyme $\mathrm{TS}^{\circledR}$, equivalente a 0,46 ppm de giberelina, a dosagem de giberelina é bem inferior ao utilizado por Lima et al. (2009), 1.000 ppm de AG3. Também Ferreira et al. (2007) observaram efeito na velocidade

da emergência utilizando concentração maior. É possível que concentrações maiores de Acadian ${ }^{\circledR}$ e Biozyme $\mathrm{TS}^{\circledR}$ possam favorecer a porcentagem e a velocidade da emergência, bem como maiores tempos de imersão. 
Tabela 1. Valores coeficiente de variação (C.V.) e de $p$ da análise de variância para os efeitos dos produtos Biozyme $\mathrm{TS}^{\circledR}$ e Acadian $^{\circledR}$, concentrações e sua interação, para as variáveis avaliadas no experimento 1. Curitiba, PR, 2012.

\begin{tabular}{lcccc}
\hline & \multicolumn{3}{c}{ Valor $p$} & \\
\cline { 2 - 4 } Variável & Produto & Concentraçã & Produto*concentraçã & C.V. (\%) \\
\hline Emergência & 0,92 & 0,71 & 0,82 & 10,1 \\
IVE & 0,28 & 0,80 & 0,83 & 3,4 \\
Comprimento do caule & 0,44 & 0,45 & 0,33 & 8,2 \\
$N^{o}$ de folhas & 0,20 & 0,68 & 0,32 & 8,2 \\
Matéria seca aérea & 0,03 & 0,00 & 0,05 & 14,5 \\
Área foliar & 0,04 & 0,86 & 0,16 & 11,2 \\
Matéria seca de raízes & 0,77 & 0,83 & 0,54 & 31,8 \\
Comprimento de raízes & 0,40 & 0,50 & 0,35 & 21,4 \\
Comprimento de raízes por classe de diâmetro (mm) & & \\
0,0 a 0,5 & 0,37 & 0,56 & 0,42 & 22,6 \\
0,5 a 1,0 & 0,18 & 0,26 & 0,31 & 25,2 \\
1,0 a 1,5 & 0,49 & 0,84 & 0,21 & 29,8 \\
1,5 a 2,0 & 0,46 & 1,00 & 0,86 & 40,1 \\
2,0 a 2,5 & 0,48 & 0,22 & 0,66 & 12,2 \\
\hline
\end{tabular}

Dentre as médias observadas para as variáveis da parte aérea comprimento do caule e número de folhas não houve diferença significativa. Porém, a massa da matéria seca da parte aérea aumentou linearmente com o incremento nas concentrações de ambos os produtos (Figura 1). As plantas cujas sementes foram tratadas com Acadian ${ }^{\circledR}$, independentemente da concentração utilizada, apresentaram maior massa de matéria seca da parte aérea do que as tratadas com Biozyme (Figura 1). Contudo, Biozyme TS ${ }^{\circledR}$ proporcionou às plântulas área foliar de $9,81 \mathrm{~cm}^{2}$ enquanto com Acadian ${ }^{\circledR}$ foi $9,03 \mathrm{~cm}^{2}$. Essa diferença foi significativa $(\mathrm{p}=0,04)$, independente da concentração (Tabela 1$)$.

Tabela 2. Médias de emergência de plântulas, índice de velocidade de emergência (IVE), comprimento do caule, número de folhas e matéria seca de raízes (MSR) de mudas de maracujazeiro-amarelo cujas sementes foram tratadas com diferentes concentrações de Biozyme TS $^{\circledR}$ e Acadian ${ }^{\circledR}$. Curitiba, PR, 2012.

\begin{tabular}{lcccccc}
\hline Produto & $\begin{array}{c}\text { Concentração } \\
\left(\mathrm{mL} \cdot \mathrm{L}^{-1}\right)\end{array}$ & $\begin{array}{c}\text { Emergência } \\
(\%)\end{array}$ & IVE & $\begin{array}{c}\text { Comprimento } \\
\text { do Caule }(\mathrm{cm})\end{array}$ & $\begin{array}{c}\mathrm{N}^{\mathrm{o}} \text { de } \\
\text { folhas }\end{array}$ & $\begin{array}{c}\text { MSR } \\
\left(\mathrm{g}^{\mathrm{p}} \text { planta }^{-1}\right)\end{array}$ \\
\hline Testemunha & 0 & $68,5^{\mathrm{ns}}$ & $20,5^{\mathrm{ns}}$ & $6,49^{\mathrm{ns}}$ & $3,38^{\mathrm{ns}}$ & $0,023^{\mathrm{ns}}$ \\
Biozyme & 2 & 71,0 & 21,0 & 6,42 & 3,44 & 0,020 \\
Biozyme & 4 & 69,6 & 20,7 & 6,21 & 3,25 & 0,023 \\
Biozyme & 6 & 69,7 & 20,6 & 6,45 & 3,31 & 0,023 \\
Acadian & 2 & 69,5 & 20,6 & 5,73 & 3,00 & 0,018 \\
Acadian & 4 & 70,1 & 20,6 & 6,46 & 3,25 & 0,035 \\
Acadian & 6 & 70,1 & 20,6 & 6,32 & 3,25 & 0,020 \\
\hline ns diferença entre tratamentos não significativa pelo teste $\mathrm{F}(\alpha=0,05)$. & &
\end{tabular}

Cultura Agronômica, Ilha Solteira, v.24, n.2, p.135-148, 2015 
Em experimento com $P$. edulis sob efeito de bioestimulante contendo cinetina, giberelina e AIB aplicado às sementes, Echer et al. (2006) observaram aumento da área foliar e da área foliar específica (área/massa), o que significa a redução da espessura da folha. Isso pode explicar a maior área foliar das plantas tratadas com Biozyme $\mathrm{TS}^{\circledR}$ e maior massa seca das tratadas com Acadian ${ }^{\circledR}$, já que a extratos de algas e alguns extratos vegetais por vezes são atribuídos efeitos similares à ação de hormônios vegetais (ZHANG et al., 2002; HONG; HIEN; SON, 2007).

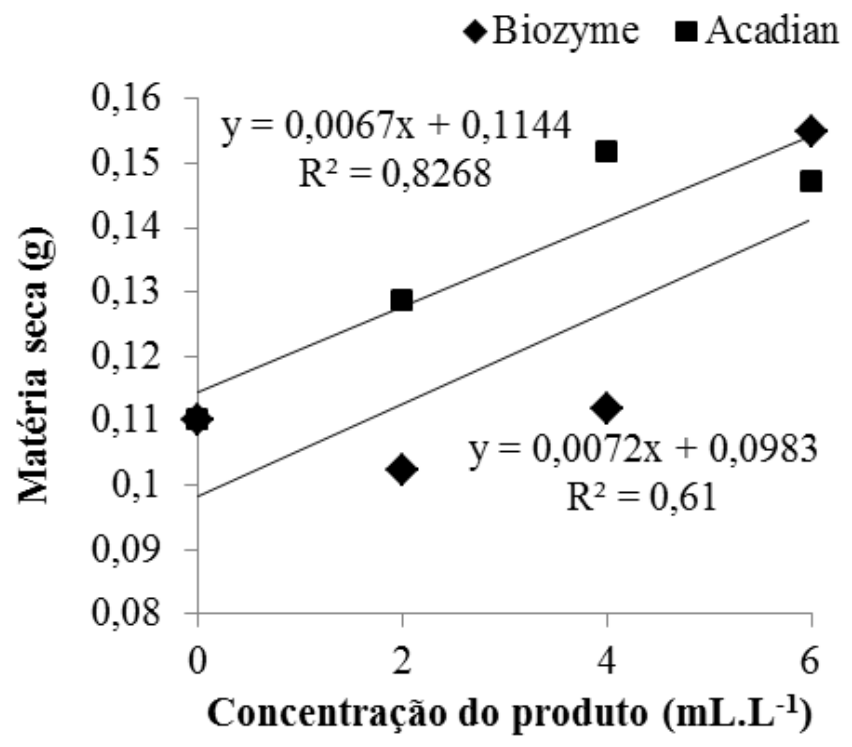

Figura 1. Matéria seca da parte aérea $\left(\mathrm{g} \mathrm{planta}^{-1}\right)$ aos 40 dias após a semeadura de mudas de maracujazeiro-amarelo cujas sementes foram tratadas com concentrações crescentes de Biozyme TS $^{\circledR}$ e Acadian $^{\circledR}$ em solução aquosa. Curitiba, PR, 2012.

Tabela 3. Médias de comprimento $(\mathrm{mm})$ de raízes de mudas de maracujazeiro-amarelo, por classe de diâmetro e total, sob efeito dos bioestimulantes Biozyme TS $^{\circledR}$ e Acadian $^{\circledR}$ aplicados às sementes em quatro concentrações aquosas. Curitiba, PR, 2012.

\begin{tabular}{|c|c|c|c|c|c|c|c|}
\hline \multirow{2}{*}{$\begin{array}{l}\text { Diâmetro } \\
(\mathrm{mm})\end{array}$} & \multirow{2}{*}{ Testemunha } & \multicolumn{3}{|c|}{ Biozyme $\left(m L . L^{-1}\right)$} & \multicolumn{3}{|c|}{ Acadian $\left(m L . L^{-1}\right)$} \\
\hline & & 2 & 4 & 6 & 2 & 4 & 6 \\
\hline & $-\ldots-\ldots$ & $-\ldots$ & Comprim & nto $(\mathrm{mm}$ & $\ldots \ldots$ & $\ldots$ & $-\ldots$ \\
\hline $0-0,5$ & $215,08^{\mathrm{ns}}$ & 222,64 & 286,40 & 211,32 & 239,64 & 222,41 & 215,39 \\
\hline $0,5-1$ & $50,21^{\mathrm{ns}}$ & 54,61 & 55,80 & 37,87 & 50,12 & 37,68 & 41,27 \\
\hline $1-1,5$ & $9,62^{\mathrm{ns}}$ & 9,59 & 12,33 & 7,53 & 11,65 & 8,89 & 9,77 \\
\hline $1,5-2$ & $2,48^{\mathrm{ns}}$ & 3,12 & 3,14 & 2,01 & 2,81 & 2,90 & 2,56 \\
\hline $2-2,5$ & $0,63^{\mathrm{ns}}$ & 0,70 & 0,95 & 0,71 & 1,18 & 0,95 & 1,03 \\
\hline $2,5-5,0$ & $0,35^{\mathrm{ns}}$ & 0,59 & 0,26 & 1,25 & 0,71 & 0,85 & 0,51 \\
\hline Total & $279,14^{\mathrm{ns}}$ & 291,70 & 359,35 & 261,65 & 306,60 & 274,35 & 271,20 \\
\hline
\end{tabular}

A maior razão entre massa seca e altura pode ser importante quando se quer produzir mudas de grande porte, pois o crescimento em altura dificulta o manejo das mesmas. Com a 
aplicação dos bioestimulantes, mudas de mesma altura que mudas controle mas com maior área foliar e matéria seca poderiam crescer melhor no pomar e ser mais precoces.

O crescimento radicular global, medido pela massa seca (Tabela 2) e a soma do comprimento das raízes (Tabela 3), não foi influenciado pelos tratamentos. De forma análoga, as quantidades médias de raízes nas classes de comprimento consideradas não demostraram efeito dos tratamentos aplicados (Tabela 3).

\section{Experimento 2}

$\mathrm{Na}$ Tabela 4 são apresentados os valores de probabilidade de erro tipo I $(p)$ e coeficientes de variação para as variáveis avaliadas no experimento 2 . O comprimento do caule, a área foliar, a matéria seca da parte aérea e o número de folhas não diferiram entre os tratamentos (Tabela 4). As médias dessas variáveis são apresentadas na Tabela 5. Já o teor de clorofila sofreu influência da aplicação dos bioestimulantes. As concentrações de 2 e 4 mL.L $\mathrm{L}^{-1}$ aumentaram o teor de clorofila das folhas, enquanto a maior concentração apresentou resultado semelhante à testemunha, configurando uma resposta do tipo quadrática (Figura 2). O concentração de máxima resposta em teor relativo de clorofila foi $3,15 \mathrm{~mL} \cdot \mathrm{L}^{-1}$.

Tabela 4. Valores do coeficiente de variação (C.V.) e de $p$ da análise de variância para os efeitos de bioestimulantes, concentrações e sua interação, para as variáveis do experimento 2. Pinhais, PR, 2012.

\begin{tabular}{lcccc}
\hline & \multicolumn{3}{c}{ Valor $p$} & \\
\cline { 2 - 4 } Variável & Produto & Concentração & Produto*concentração & C.V. $(\%)$ \\
\hline Comprimento do caule & 0,50 & 0,06 & 0,96 & 11,2 \\
$N^{o}$ de folhas & 0,08 & 0,17 & 0,74 & 12,8 \\
Matéria seca aérea & 0,40 & 0,96 & 0,35 & 15,6 \\
Área foliar & 0,75 & 0,74 & 0,34 & 19,6 \\
Clorofila & 0,61 & 0,02 & 0,57 & 8,9 \\
Matéria seca de raízes & 0,44 & 0,07 & 0,19 & 20,8 \\
Comprimento de raízes & 0,53 & 0,43 & 0,20 & 20,3 \\
& Comprimento de raízes por classe de diâmetro & \\
0,0 a $0,5 \mathrm{~mm}$ & 0,19 & 0,25 & 0,25 & 18,6 \\
0,5 a $1,0 \mathrm{~mm}$ & 0,58 & 0,64 & 0,27 & 22,3 \\
1,0 a $1,5 \mathrm{~mm}$ & 0,79 & 0,95 & 0,30 & 27,6 \\
1,5 a $2,0 \mathrm{~mm}$ & 0,63 & 0,91 & 0,17 & 28,0 \\
2,0 a $2,5 \mathrm{~mm}$ & 0,78 & 0,80 & 0,09 & 29,5 \\
2,5 a 3,0 mm & 0,23 & 0,33 & 0,12 & 32,5 \\
3,0 a 3,5 mm & 0,17 & 0,29 & 0,04 & 33,3 \\
3,5 a 4,0 mm & 0,66 & 0,01 & 0,10 & 42,1 \\
4,0 a 4,5 mm & 0,19 & 0,18 & 0,22 & 52,3 \\
4,5 a 5,0 mm & 0,03 & 0,12 & 0,12 & 0,62 \\
\hline
\end{tabular}

Blunden, Jenkins e Liu (1997) observaram aumento nos teores de clorofila nas folhas de milho, tomate e cevada após aplicações de extrato A. nodosum via foliar. Esse efeito foi atribuído à presença de betaínas no extrato da alga, as quais reduzem a degradação da

Cultura Agronômica, Ilha Solteira, v.24, n.2, p.135-148, 2015 
clorofila (WHAPHAM et al., 1993). Apesar disso a concentração de 6,0 mL.L ${ }^{-1}$ não causou esse efeito. Isso pode ser explicado pelo efeito em baixas concentrações (KHAN et al., 2009). Altas concentrações inibiram o efeito de extrato da alga Ecklonia maxima (FINNIE; VAN STADEN, 1985) e A. nodosum (STIRK; VAN STADEM, 1996; OLIVEIRA et al., 2011). No caso dos tratamentos com Biozyme $\mathrm{TS}^{\circledR}$ o aumento o teor relativo de clorofila nas folhas pode ser explicado pela provável existência de zeatina em sua composição, citocinina que, segundo Taiz e Zieger (2004), promove a síntese de pigmentos e proteínas fotossintéticas.

Tabela 5. Médias de área foliar (AF), comprimento do caule, número de folhas e matéria seca da parte aérea (MAS) e radicular (MSR) de mudas de maracujazeiro-amarelo tratadas com diferentes concentrações de Biozyme TS $^{\circledR}$ e Acadian ${ }^{\circledR}$ em pulverização foliar. Pinhais, PR, 2012.

\begin{tabular}{lcccccc}
\hline Produto & $\begin{array}{c}\text { Concentração } \\
\left(\mathrm{mL} . \mathrm{L}^{-1}\right)\end{array}$ & $\begin{array}{c}\mathrm{AF} \\
\left(\mathrm{cm}^{2}\right)\end{array}$ & $\begin{array}{c}\text { Caule } \\
(\mathrm{cm})\end{array}$ & $\begin{array}{c}\mathrm{N}^{\mathrm{o}} \mathrm{de} \\
\text { folhas }\end{array}$ & $\begin{array}{c}\text { MAS } \\
(\mathrm{g})\end{array}$ & $\begin{array}{c}\text { MSR } \\
(\mathrm{g})\end{array}$ \\
\hline Testemunha & 0 & $84.2^{\mathrm{ns}}$ & $9.41^{\mathrm{ns}}$ & $5.0^{\mathrm{ns}}$ & $0.59^{\mathrm{ns}}$ & $0.73^{\mathrm{ns}}$ \\
Biozyme & 2 & 75.5 & 11.13 & 4.6 & 0.60 & 0.62 \\
Biozyme & 4 & 70,0 & 10.21 & 4.8 & 0.53 & 0.72 \\
Biozyme & 6 & 84.2 & 9.98 & 4.8 & 0.61 & 0.78 \\
Acadian & 2 & 75.7 & 10.78 & 4.1 & 0.58 & 0.55 \\
Acadian & 4 & 87.9 & 10.05 & 4.1 & 0.66 & 0.83 \\
Acadian & 6 & 73.1 & 9.39 & 4.4 & 0.62 & 0.57 \\
\hline
\end{tabular}

${ }^{\text {ns }}$ diferença entre tratamentos não significativa pelo teste $\mathrm{F}(\alpha=0,05)$.

$$
\begin{gathered}
y=-3,6849 x^{2}+23,27 x+523,26 \\
R^{2}=0,658
\end{gathered}
$$

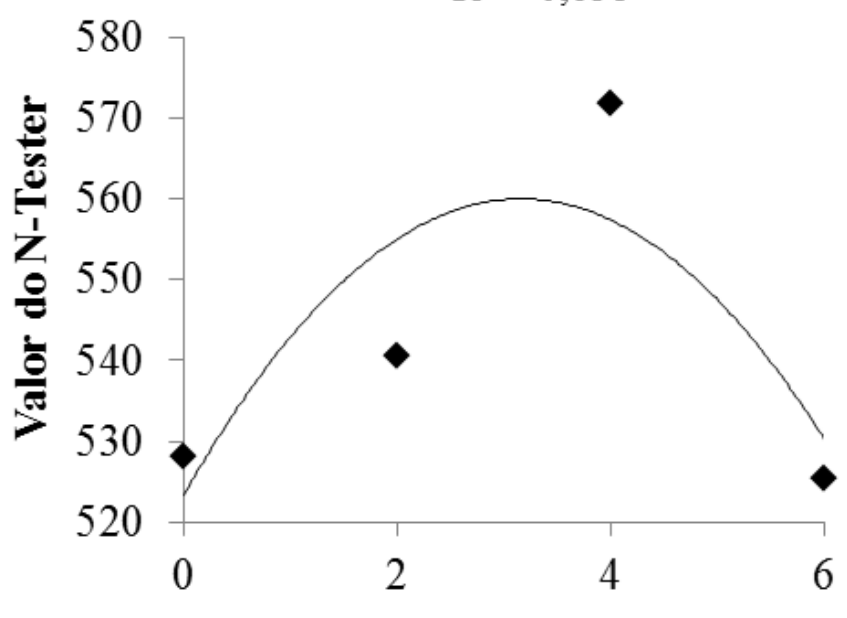

Concentração do produto $\left(\mathrm{mL} . \mathrm{L}^{-1}\right)$

Figura 2. Teor relativo de clorofila (valor medido pelo clorofilômetro N-Tester, adimensional) em folhas de maracujazeiro-amarelo sete dias após a aplicação de concentrações de Biozyme $\mathrm{TS}^{\circledR}$ e $\operatorname{Acadian}^{\circledR}\left(\mathrm{mL}^{\circledR} \mathrm{L}^{-1}\right)$ por pulverização foliar. Pinhais, PR, 2012. 


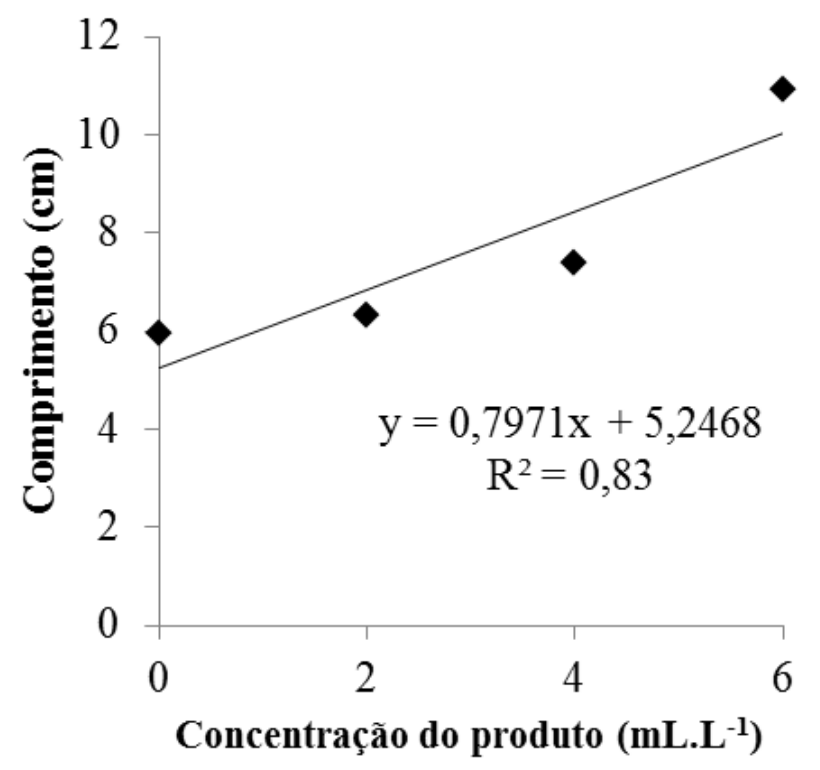

Figura 3. Efeito de concentrações do bioestimulante Biozyme $\mathrm{TS}^{\circledR}\left(\mathrm{mL} \cdot \mathrm{L}^{-1}\right)$ em pulverização foliar no comprimento total das de raízes de maracujazeiro-amarelo com diâmetro entre 3,0 e 3,5 mm. Pinhais, PR, 2012.

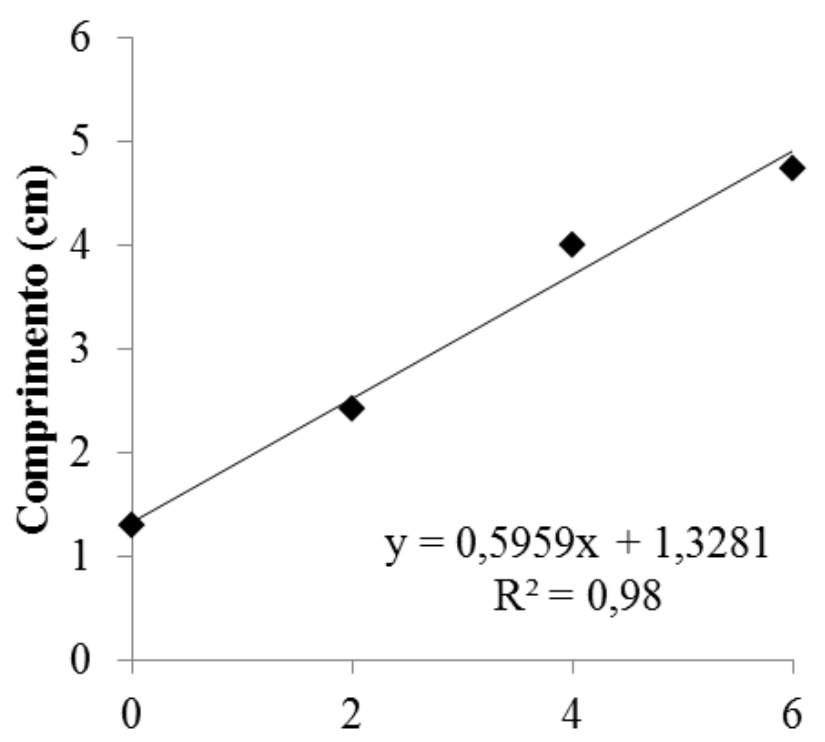

Concentração do produto (mL. $\left.\mathrm{L}^{-1}\right)$

Figura 4. Efeito de concentrações dos bioestimulantes Biozyme $\mathrm{TS}^{\circledR}$ e Acadian ${ }^{\circledR}$ em pulverização foliar no comprimento total de raízes de maracujazeiro-amarelo com diâmetro entre 3,5 e 4,0 mm. Pinhais, PR, 2012.

Apesar de não se ter observado efeito significativo na matéria seca e no comprimento total das raízes (Tabela 4), os bioestimulantes aumentaram a quantidade de raízes grossas. A aplicação de Biozyme $\mathrm{TS}^{\circledR} \mathrm{em}$ concentrações crescentes provocou aumento linear na quantidade de raízes de 3,0 a 3,5 mm de diâmetro (Figura 3). Já para a classe de 3,5 a 4,0 Cultura Agronômica, Ilha Solteira, v.24, n.2, p.135-148, 2015 
$\mathrm{mm}$, o aumento da concentração de ambos os produtos resultou em incremento linear da quantidade de raízes (Figura 4). Esse efeito resultou em uma maior quantidade de raízes de grande diâmetro, facilmente observado no tratamento 6 mL.L ${ }^{-1}$ de Biozyme TS ${ }^{\circledR}$ (Figura 5). Para as demais classes de diâmetro de raízes e para o comprimento total de raízes não se observou efeito dos tratamentos. As médias observadas são apresentadas na Tabela 6.

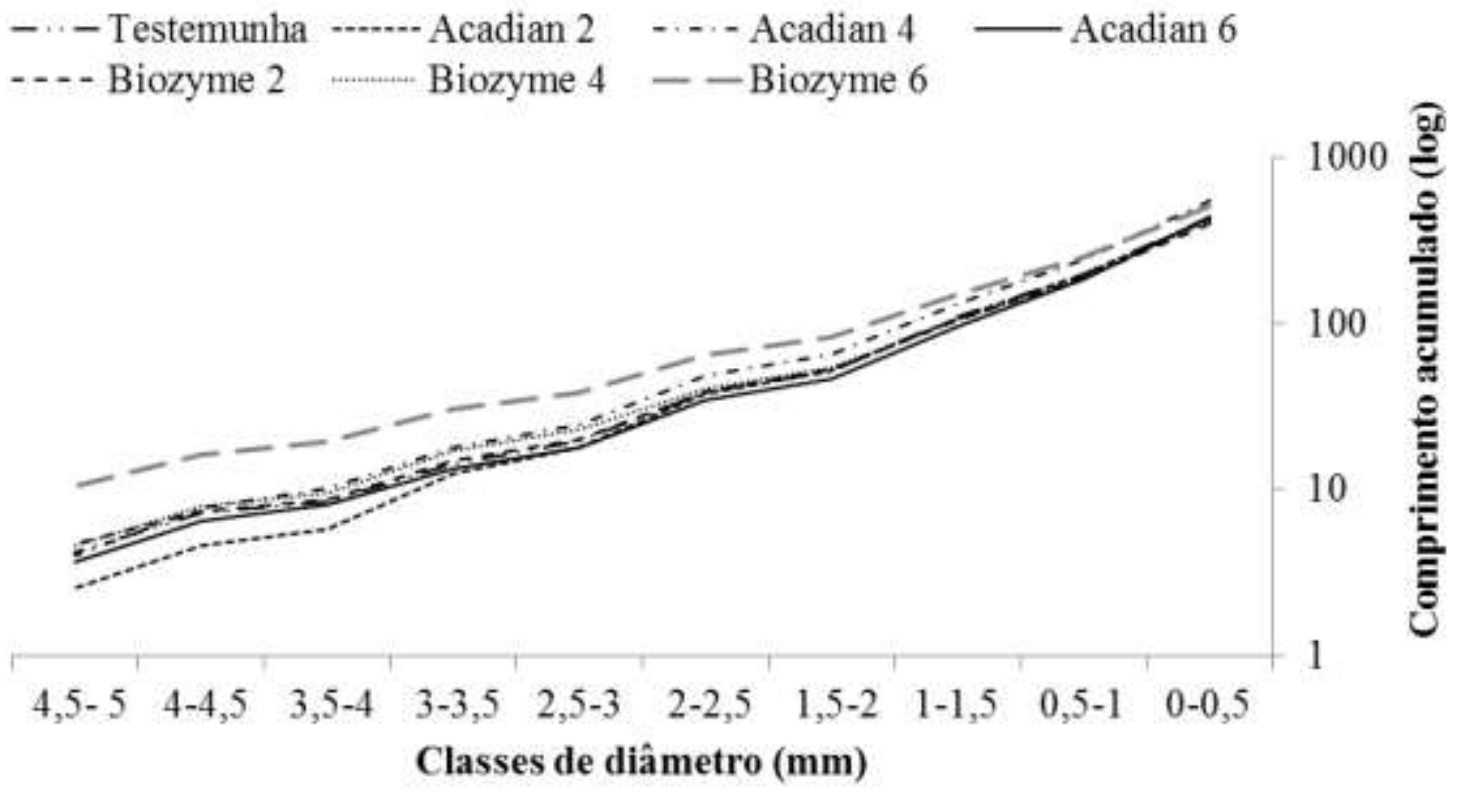

Figura 5. Comprimento de raízes acumulado de acordo com o decréscimo do diâmetro das raízes nos tratamentos com Biozyme $\mathrm{TS}^{\circledR}$ e Acadian ${ }^{\circledR}$ em diferentes concentrações $(2,4$ a 6 $\left.\mathrm{mL} . \mathrm{L}^{-1}\right)$ e na testemunha. Curvas mais elevadas indicam maior quantidade de raízes grossas. A escala é logarítmica. Pinhais, PR, 2012.

Tabela 6. Médias de comprimento $(\mathrm{mm})$ de raízes de mudas de maracujazeiro-amarelo, por classe de diâmetro (mm), sob efeito dos bioestimulantes Biozyme TS $^{\circledR}$ e Acadian ${ }^{\circledR}$ aplicados sobre as folhas em quatro concentrações aquosas. Pinhais, PR, 2012.

\begin{tabular}{|c|c|c|c|c|c|c|c|}
\hline \multirow[b]{2}{*}{$\begin{array}{c}\text { Classes de } \\
\text { diâmetro }\end{array}$} & \multirow[b]{2}{*}{ Testemunha } & \multicolumn{3}{|c|}{ Biozyme (mL.L $\left.{ }^{-1}\right)$} & \multicolumn{3}{|c|}{ Acadian $\left(\mathrm{mL} . \mathrm{L}^{-1}\right)$} \\
\hline & & 2 & 4 & 6 & 2 & 4 & 6 \\
\hline $0-0,5 \mathrm{~mm}$ & $210,80^{\mathrm{ns}}$ & 227,42 & 255,52 & 235,80 & 231,13 & 303,85 & 246,04 \\
\hline $0,5-1 \mathrm{~mm}$ & $85,87^{\mathrm{ns}}$ & 84,89 & 101,27 & 89,02 & 87,55 & 112,78 & 88,17 \\
\hline $1-1,5 \mathrm{~mm}$ & $51,67^{\mathrm{ns}}$ & 50,52 & 64,61 & 56,35 & 56,27 & 66,37 & 50,20 \\
\hline $1,5-2 \mathrm{~mm}$ & $13,91^{\mathrm{ns}}$ & 13,37 & 17,98 & 14,05 & 13,87 & 16,68 & 11,93 \\
\hline $2-2,5 \mathrm{~mm}$ & $18,54^{\mathrm{ns}}$ & 17,60 & 25,91 & 18,75 & 19,48 & 23,73 & 16,44 \\
\hline $2,5-3 \mathrm{~mm}$ & $5,24^{\mathrm{ns}}$ & 6,31 & 8,47 & 5,16 & 5,39 & 6,60 & 4,66 \\
\hline $3-3,5 \mathrm{~mm}$ & $6,30^{\mathrm{ns}}$ & 7,38 & 10,91 & 5,96 & 6,83 & 7,84 & 5,20 \\
\hline $3,5-4 \mathrm{~mm}$ & $1,20^{\mathrm{ns}}$ & 1,66 & 2,96 & 1,30 & 1,22 & 2,35 & 1,79 \\
\hline $4-4,5 \mathrm{~mm}$ & $2,70^{\mathrm{ns}}$ & 3,36 & 5,77 & 2,94 & 2,06 & 3,72 & 2,75 \\
\hline $4,5-5 \mathrm{~mm}$ & $4,77^{\mathrm{ns}}$ & 4,60 & 10,60 & 4,28 & 2,55 & 4,09 & 3,69 \\
\hline Total & $402,80^{\mathrm{ns}}$ & 420,54 & 506,53 & 435,86 & 428,71 & 550,88 & 433,18 \\
\hline
\end{tabular}

${ }^{n s}$ diferença entre tratamentos não significativa pelo teste $\mathrm{F}(\alpha=0,05)$. 
O estímulo ao crescimento radicular pode ser atribuído à provável presença de auxinas nos produtos em teste. Extrato de A. nodosum aplicado em calos de Glycine max provoca incremento no número de raízes emitidas, de forma análoga à aplicação de ácido indolbutírico (STIRK; VAN STADEM, 1996). A auxina, que é naturalmente produzida nos meristemas apicais aéreos, é exigida em baixas concentrações para o crescimento de raízes. Altas concentrações inibem seu crescimento. Nos caules de plantas intactas a concentração natural de auxina é próxima à ótima. Aplicações exógenas podem ser inibitórias ou ter um efeito modesto (TAIZ; ZEIGER, 2004).

Em aplicação foliar, a concentração estimada de $3,15 \mathrm{~mL} \cdot \mathrm{L}^{-1}$ de bioestimulante proporcionou melhor crescimento das raízes em relação à testemunha sem deprimir o teor de clorofila das folhas. Essa concentração é próxima da considerada a ideal por Oliveira et al. (2011), que observaram melhor crescimento da parte aérea das plantas com 4 mL.L ${ }^{-1}$ de Acadian $^{\circledR}$, mas não observaram efeito no crescimento radicular. Deve ser considerado que naquele trabalho as plantas eram menores, assemelhando-se às do Experimento 1 do presente trabalho. É possível que a resposta das plantas ao produto seja dependente do estádio fenológico em que se encontram, visto que, no presente Experimento 1, verificou-se efeito na parte aérea mas não da radicular, concordando com o trabalho supracitado.

\section{CONCLUSÃO}

A aplicação de Biozyme TS $^{\circledR}$ e de Acadian $^{\circledR}$ às sementes de maracujazeiro-amarelo até a concentração de $6 \mathrm{~mL} \cdot \mathrm{L}^{-1}$ aumenta a matéria seca da parte aérea de plântulas de maracujazeiro-amarelo. A aplicação de Biozyme TS $^{\circledR}$ e Acadian ${ }^{\circledR}$ nas concentrações de 3,15 mL.L $L^{-1}$ via aspersão foliar promove máximo teor relativo de clorofila nas folhas. As aplicações de Acadian $^{\circledR}$ e de Biozyme TS $^{\circledR}$ nas folhas na concentração de até 6 mL.L ${ }^{-1}$ aumenta a quantidade de raízes grossas em mudas de maracujazeiro-amarelo.

\section{AGRADECIMENTOS}

A Coordenação de Aperfeiçoamento de Pessoal de Nível Superior (CAPES) e Conselho de Desenvolvimento Científico e Tecnológico (CNPq) pelas bolsas concedidas.

\section{REFERÊNCIAS BIBLIOGRÁFICAS}

BLUNDEN, G.; JENKINS, T.; LIU, Y.-W. Enhanced leaf chlorophyll levels in plants treated with seaweed extract. Journal of Applied Phycology, Dordrecht, v. 8, n. 6, p.535$543,1997$.

ECHER, M. M.; GUIMARÃES, V. F.; KRIESER, C. R.; ABUCARMA, V. M.; KLEIN, J.; SANTOS, L.; DALLABRIDA, W. R. Uso de bioestimulante na formação de mudas de maracujazeiro amarelo. Semina: Ciências Agrárias, Londrina, v. 27, n. 3, p.351-360, 2006.

Cultura Agronômica, Ilha Solteira, v.24, n.2, p.135-148, 2015 
FERREIRA, G.; COSTA, P. N.; FERRARI, T. B.; RODRIGUES, J. D.; BRAGA, J. F.; JESUS, F. A.. Emergência e desenvolvimento de plântulas de maracujazeiro azedo oriundas de sementes tratadas com bioestimulante. Revista Brasileira de Fruticultura, Jaboticabal, v. 29, n. 3, p.595-599, 2007.

FERREIRA, E. B.; CAVALCANTI, P. P.; NOGUEIRA, D. A. Experimental Designs: um pacote R para análise de experimentos. Revista da Estatística da UFOP, Ouro Preto, v. 1, n. 1, p.1-9, 2011.

FINNIE, J. F.; VAN STADEN, J. Effect of seaweed concentrate and applied hormones on in vitro cultured tomato roots. Journal of Plant Physiology, Stuttgart, v. 120, n. 3, p.215222, $1985 . \quad$ Disponível em: < http://www.sciencedirect.com/science/article/pii/S0176161785801085>. Acesso em: 03 fev. 2013.

HONG, D. D.; HIEN, H. M.; SON, P. N. Seaweeds from Vietnam used for functional food, medicine and biofertilizer. Journal of Applied Phycology, Dordrecht, v. 19, n. 6, p.817826, 2007.

INSTITUTO BRASILEIRO DE GEOGRAFIA E ESTATÍSTICA. Sistema IBGE de recuperação automática. 2014. Disponível em: < http://www.sidra.ibge.gov.br/bda/pesquisas/pam/default.asp >. Acesso em: 24 jun. 2014.

KHAN, W.; RAYIRATH, U. P.; SUBRAMANIAN, S.; JITHESH, M. N.; RAYORATH, P. R.; HODGES, D. M.; CRITCHLEY, A. T.; CRAIGIE, J .S.; NORRIE, J.; PRITHIVIRAJ, B. Seaweed extracts as biostimulants of plant growth and development. Journal of Plant Growth Regulation, New York, v. 28, n. 4, p.386-399, 2009. Disponível em: < http://link.springer.com/article/10.1007\%2Fs00344-009-9103-x>. Acesso em: 20 jan. 2013.

KOYAMA, R.; BETTONI, M. M.; RODER, C.; ASSIS, A. M.; ROBERTO, S. R.; MÓGOR, A. F. Extrato da alga Ascophyllum nodosum (L.) Le Jolis no desenvolvimento vegetativo e na produção do tomateiro. Revista de Ciências Agrárias, Belém, v. 55, n. 4, p.

282-287, 2012. Disponível em: < http://www.periodicos.ufra.edu.br/index.php?journal=ajaes\&page=article \&op=view\&path $\%$ 5B\%5D=559>. Acesso em: 28 jul. 2014.

LIMA, A. A.; CALDAS R. C.; SANTOS V. S. Germinação e crescimento de espécies de maracujá. Revista Brasileira de Fruticultura, Jaboticabal, v. 28, n. 1, p.125-127, 2006.

LIMA, C. S. M.; BETEMPS, D. L.; TOMAZ, A. F. P.; GALARÇA, S. P.; RUFATO, A. R. Germinação de sementes e crescimento de maracujá em diferentes concentrações do ácido giberélico, tempos de imersão e condições experimentais. Revista Brasileira de Agrociência, Pelotas, v. 15, n. 1, p.43-48, 2009.

Cultura Agronômica, Ilha Solteira, v.24, n.2, p.135-148, 2015 
MÓGOR, A. F.; ONO, E. O.; RODRIGUES, J. D.; MÓGOR, G. Aplicação foliar de extrato de alga, ácido L-glutâmico e cálcio em feijoeiro. Scientia Agraria, Curitiba, v. 9, n. 4, p.431-437, 2008.

NESI, C. N.; KUHN, T. M. A.; ARAUJO, E. S.; MÓGOR, Á. F.; DE MIO, L. L. M. Avaliação de extrato de algas no progresso temporal da mancha de mycosphaerella em cultivares de morangueiro. Ceres, Viçosa, v. 60, n. 1, p.38-42, 2013. Disponível em em: < http://www.scielo.br/pdf/rceres/v60n1/06.pdf>. Acesso em: 28 jul. 2014.

OliveIRA, L. A. A.; GÓES, G. B.; MELO, I. G. C. M.; COSTA, M. E.; SILVA, R. M. Uso do extrato de algas (Ascophyllum nodosum) na produção de mudas de maracujazeiroamarelo. Revista Verde de Agroecologia e Desenvolvimento Sustentável, Mossoró, v. 6, n. 2, p.1-4, 2011. Disponível em: < http://www.gvaa.com.br/revista/index.php/RVADS/article/view/640>. Acesso em: 22 ago. 2012.

PERES, J. C. F.; CARVALHO, L. R.; GONÇALEZ, E.; BERIAN, L. O. S.; FELICIO, J. D. Evaluation of antifungal activity of seaweed extracts. Ciência e Agrotecnologia, Lavras, v. 36, n. 3, p.294-299, 2012. Disponível em: 〈http://www.scielo.br/pdf/cagro/v36n3/04.pdf〉. Acesso em: 28 jul. 2014.

PRADO, R. M.; NATALE, W.; ROZANE, D. E. Níveis críticos de boro no solo e na planta para cultivo de mudas de maracujazeiro-amarelo. Revista Brasileira de Fruticultura, Jaboticabal, v. 28, n. 2, p.305-309, 2006.

ROSSETO, C. A. V.; CONEGLIAN, R. C. C.; NAKAGAWA, J.; SHIMIZU, M. K.; MARIN, V. A. Germinação de sementes de maracujá-doce (Passiflora alata Dryand) em função de tratamento pré-germinativo. Revista Brasileira de Sementes, Pelotas, v. 22, n. 1, p.247-252, 2000.

STIRK, W. A.; VAN STADEN, J. Comparison of cytokinin- and auxinlike activity in some commercially used seaweed extracts. Journal of Applied Phycology, Dordrecht, v. 8, n. 6, p.503-508, 1996.

TAIZ, L.; ZEIGER, E. Fisiologia vegetal. Tradução por SANTARÉM, E. R. 3. ed. São Paulo: Artmed, 2004. 719 p.

WHAPHAM, C. A.; BLUNDEN, G.; JENKINS, T.; HANKINS, S. D. Significance of betaines in the increased chlorophyll content of plants treated with seaweed extract. Journal of Applied Phycology, Dordrecht, v. 5, n. 2, p.231-234, 1993.

Cultura Agronômica, Ilha Solteira, v.24, n.2, p.135-148, 2015 
ZHANG, X.; SCHMIDT, R. E.; ERVIN, E. H.; DOAK, S. Creeping bentgrass physiological responses to natural plant growth regulators and iron under two regimes. Hortscience, Alexandria, v. 37, n. 6, p.898-902, 2002.

ZUCARELI, V.; FERREIRA, G.; AMARO, A. C. E.; FAZIO, J. L. GA4+7+ N(Fenilmetil)-aminopurina na germinação de sementes e emergência de plântulas de Passiflora cincinnata Mast. Revista Brasileira de Fruticultura, Jaboticabal, v. 31, n. 1, p.216-223, 2009. 